\title{
Desterritorização e reterritorização: processos vivenciados por jovens com deficiência intelectual no contexto da inclusão escolar
}

Deterritorialization and reterritorialisation: youth in experienced processes with intellectual disabilities in the context of school inclusion

Desterritorización y reterritorización: procesos vivenciados por jóvenes con discapacidad intelectual en el contexto de la inclusión escolar

\section{* Valéria Becher Trentin}

Doutoranda pela Universidade do Vale do Itajaí, Itajaí, Santa Catarina, Brasil.

valeriatret@yahoo.com.br

Recebido em 21 de setembro de 2017

Aprovado em 24 de outubro de 2018

Publicado em 06 de maio de 2019

\section{RESUMO}

Após a promulgação da Política Nacional de Educação Especial na Perspectiva da Educação Inclusiva (BRASIL, 2008), a inclusão de pessoas com deficiência na modalidade da Educação de Jovens e Adultos está ocorrendo de maneira mais acentuada. Mediante essa inclusão, o presente artigo tem por objetivo compreender os processos de desterrittorização e de reterritorização, vivenciados por jovens com deficiência intelectual no contexto da inclusão escolar. De abordagem qualitativa se utilizou como instrumento de coleta de dados a entrevista semiestruturada e, como sujeitos 3 (três) jovens com deficiência intelectual matriculados em um Centro de Educação de Jovens e Adultos (CEJA), situado no Estado de Santa Catarina. A pesquisa foi construída com concepções advindas dos estudos territoriais especialmente nos conceitos de território, desterritorialização e reterritorialização de Deleuze e Guattari (1995;1997), que propiciaram diálogo com a pesquisa. Constatou-se que a inclusão possibilitou aos jovens com deficiência intelectual a descoberta de novos territórios. Nessa descoberta, os jovens vivenciam processos de desterritorização e reterritorização. Na desterritorização, emergem as linhas de fuga, perfilhando uma relação entre o desejo e o pensamento, a terra e o território, em que as experiências vivenciadas na escola especial são acompanhadas pela reterritorização no CEJA. Por meio destes procesos, os jovens com deficiência intelectual fazem parte do devir que a inclusão escolar possibilita.

Palavras-chave: Jovens com deficiência intelectual; Desterritorialização; Reterritorialização. 


\section{ABSTRACT}

Following the promulgation of the National Policy on Special Education in the Perspective of Inclusive Education (BRASIL, 2008), the inclusion of people with disabilities in the modality of Youth and Adult Education is occurring in a more pronounced way. Through this inclusion, this article aims to understand the processes of deterritorization and reterritorization experienced by young people with intellectual disabilities in the context of school inclusion. From a qualitative approach, the semi-structured interview was used as a data collection instrument and as subjects 3 (three) young people with intellectual disabilities enrolled in a Center for Youth and Adult Education (CEJA), located in the State of Santa Catarina. The research was constructed with concepts derived from territorial studies, especially in the concepts of territory, deterritorialization and reterritorialisation of Deleuze and Guattari (1995, 1997), who provided a dialogue with the research. It was found that inclusion made it possible for young people with intellectual disabilities to discover new territories. In this discovery, young people experience processes of de-territorialization and reterritorization. In demarranging, escape lines emerge, forming a relationship between desire and thought, land and territory, where experiences experienced in the special school are accompanied by reterritorization in the CEJA. Through these processes the young people with intellectual disability, are part of the becoming that the school inclusion makes possible.

Keywords: Young people with intellectual disabilities; Deterritorialization; Reterritorialisation

\section{RESUMEN}

Después de la promulgación de la Política Nacional de Educación Especial en la Perspectiva de la Educación Inclusiva (BRASIL, 2008), la inclusión de personas con discapacidad en la modalidad de la Educación de Jóvenes y Adultos está ocurriendo de manera más acentuada. Mediante esta inclusión, el presente artículo tiene por objetivo comprender los procesos de desterrittorización y de reterritorización, vivenciados por jóvenes con discapacidad intelectual en el contexto de la inclusión escolar. De abordaje cualitativo se utilizó como instrumento de recolección de datos la entrevista semiestructurada y, como sujetos 3 (tres) jóvenes con discapacidad intelectual matriculados en un Centro de Educación de Jóvenes y Adultos (CEJA), situado en el Estado de Santa Catarina. La investigación fue construida con concepciones derivadas de los estudios territoriales especialmente en los conceptos de territorio, desterritorialización y reterritorialización de Deleuze y Guattari (1995, 1997), que propiciaron diálogo con la investigación. Se constató que la inclusión permitió a los jóvenes con discapacidad intelectual el descubrimiento de nuevos territorios. En ese descubrimiento, los jóvenes experimentan procesos de desterritorización y reterritorización. En la desterritorización, emergen las líneas de fuga, perfilando una relación entre el deseo y el pensamiento, la tierra y el territorio, en que las experiencias vivenciadas en la escuela especial son acompañadas por la reterritorización en el CEJA. Por medio de estos procesos, los jóvenes con discapacidad intelectual forman parte del devenir que la inclusión escolar posibilita.

Palabras clave: Jóvenes con discapacidad intelectual; despojo; Toma de posesión. 


\title{
Introdução
}

O direito à educação para todos tem sido um dos principais temas de discussão nas últimas décadas. Na década de 90 ocorreram movimentos internacionais, que tinham como slogan "A Educação para Todos", como a Declaração Mundial de Educação para Todos (1990) e a Declaração de Salamanca (1994), que proclamaram a necessidade de criação de políticas públicas educacionais direcionadas à igualdade de oportunidades. O pressuposto de uma inclusão escolar efetiva, que assegure o direito de igualdade com equidade para todos, vem sendo abordada nos documentos nacionais, entre eles o documento subsidiário à Política de Inclusão (BRASIL, 2007), o qual demonstra ideias sobre o movimento inclusivo:

\begin{abstract}
As duas últimas décadas foram marcadas pelo debate da inclusão, estabelecendo como componente fundamental a universalização do acesso à educação, o desenvolvimento de uma pedagogia centrada na criança, a ampliação da participação da família e da comunidade, a organização das escolas para a participação e aprendizagem de todos os alunos e a formação de redes de apoio a inclusão. Esta postura ativa de identificação das barreiras que alguns alunos encontram no acesso à educação e também a busca dos recursos necessários para ultrapassá-los se constituiu no movimento da inclusão e da consolidação de um novo paradigma educacional referenciado na concepção de educação inclusiva, que tem como desafio a construção de uma escola aberta às diferenças e uma sociedade que reconhece e valoriza a diversidade. (BRASIL, 2007, p. 47-48)
\end{abstract}

A inclusão escolar se apresenta como uma perspectiva na qual a matrícula do aluno com deficiência, síndromes e transtornos globais do desenvolvimento, não é suficiente para que esta se torne inclusiva. A inclusão escolar visa transformações que promovam a "[...] igualdade de oportunidades, respeito às necessidades individuais, qualidade no processo de ensino-aprendizagem, melhoria das condições de trabalho dos professores, maior participação das famílias e da sociedade em geral, remoção das barreiras para aprendizagem e participação." (CARVALHO, 2004, p.79). Assim, entende-se que as transformações nas escolas não são uma mera exigência da inclusão de pessoas com deficiência. As transformações devem ser vistas como um compromisso inadiável, que terá a inclusão escolar como consequência. Frente as transformações que essa inclusão pressupõe, destaca-se o estreitamento entre a Educação Especial e a Educação Comum, para atender à diversidade presente nas salas de aulas, do ensino regular, em todos os níveis e na modalidade da Educação de Jovens e Adultos.

A inclusão de pessoas com deficiência na modalidade da Educação de Jovens e Adultos está ocorrendo de maneira mais acentuada nos últimos anos, como consequência da ampliação do acesso ao ensino regular. Os dados do Censo Escolar da Educação 
Básica, divulgados pelo Instituto de Estudo e Pesquisas Educacionais Anísio Teixeira (INEP), por meio dos microdados da Educação Básica, indicaram que, no ano de 2013, houve matrícula de 3.772,670 pessoas na Educação de Jovens e Adultos e, destes 51.074 público alvo da Educação Especial. (BRASIL, 2015). Diante destes números, observa-se significativa mudança no perfil dos alunos atendidos pela modalidade da EJA, os quais não se restringem mais à pessoas que não tiveram acesso à escolarização em época apropriada, mas também aos que, mesmo escolarizados, não tiveram aprendizagens significativas para o desenvolvimento e participação plena nos contextos sociais, notadamente os jovens com deficiência intelectual. Mediante este cenário, cabe questionar: que processos são vivenciados pelos jovens com deficiência intelectual no contexto da inclusão escolar? Buscou-se resposta ao questionamento nos estudos territoriais especialmente nos conceitos de território, desterritorialização e reterritorialização de Deleuze e Guattari (1996; 1997), que propiciaram diálogo com a pesquisa. Neste sentido, o presente artigo tem por objetivo compreender os processos vivenciados por jovens com deficiência intelectual no contexto da inclusão escolar.

O artigo encontra-se dividido em três seções principais. Na primeira seção, apresentase um diálogo entre a inclusão escolar e os estudos territoriais, que possibilitou a adoção dos conceitos de desterritorização e reterritorização como categorias de análise para a compreensão dos processos vivenciados por jovens com deficiência intelectual no contexto da inclusão escolar. Na segunda seção, apresenta-se a análise dos enunciados dos jovens com deficiência intelectual, compreendidos como processos de desterritorização e reterritorização e na terceira as considerações finais.

\section{Metodologia}

Com a intenção de compreender os processos, vivenciados por jovens com deficiência intelectual no contexto da inclusão escolar, especialmente na EJA, foi realizada pesquisa de abordagem qualitativa, com 3 (três) jovens com deficiência intelectual matriculados em um Centro de Educação de Jovens e Adultos (CEJA), localizado em um município do Estado de Santa Catarina.

Como instrumento de coleta de dados, utilizou-se a entrevista semiestruturada que, segundo Bauer e Gaskell (2002, p. 64), precisa pressupor que o mundo social não é um dado natural, sem problemas, pois "Ele é ativamente constituído por pessoas em suas vidas cotidianas, mas não sob condições que elas mesmas estabeleceram", como também se 
http://dx.doi.org/10.5902/1984686X24095

assume "que essas construções constituem a realidade essencial das pessoas, e de seu mundo vivencial." Os autores elucidam que,

\begin{abstract}
O emprego da entrevista qualitativa para mapear e compreender o mundo da vida dos respondentes é o ponto de entrada para os esquemas interpretativos e compreender as narrativas dos atores, em termos mais conceptuais e abstratos, pois fornece os dados básicos para o desenvolvimento e a compreensão das relações entre os atores sociais e sua situação (BAUER e GASKELL, 2002, p. 64).
\end{abstract}

As entrevistas com os 3 (três) jovens foram realizadas no CEJA. Utilizou-se com o consentimento dos entrevistados o gravador. Após a realização das entrevistas, fez-se a transcrição, com o cuidado de manter fidelidade a todos os dizeres e expressões dos entrevistados. As narrativas produzidas durante as entrevistas foram analisadas, com "olhar teórico" dos estudos territoriais, especialmente nos conceitos de desterritorialização e reterritorialização de Deleuze e Guattari (1995; 1997).

\title{
Inclusão de jovens com deficiência intelectual na modalidade educação de jovens e adultos em Santa Catarina: o ceja como um novo território
}

O direito à educação para todos tem sido um dos principais temas de discussão nas últimas décadas. Discussões sobre a temática no Brasil emergiram após a Declaração dos Direitos Humanos em 1948, que foi promulgada pela Organização das Nações Unidas (ONU), cujos princípios se pautavam na igualdade, liberdade e fraternidade. O Brasil pautado nos princípios de igualdade anunciados na Declaração dos Direitos Humanos (1948) promulgou em 1988, a Constituição Federal, que passou a assegurar direitos e garantias. Mediante direitos e garantias, a CF/1988 em seu artigo 205, assegura a educação como direito de todos, e, no artigo 206 e 208, estabelece igualdade de condições de acesso e permanência na escola, sendo dever do Estado garantir a oferta do Atendimento Educacional Especializado (AEE), preferencialmente na rede regular de ensino (BRASIL, 1988). Os direitos e garantias contidos na CF/1988 são decorrentes de ampla discussão nacional e da influência de inúmeros movimentos.

Na década de 90 ocorreram movimentos internacionais, que tinham como slogan " $A$ Educação para Todos", como a Declaração Mundial de Educação para Todos (1990) e a Declaração de Salamanca (1994), que proclamaram a necessidade de criação de políticas públicas educacionais direcionadas à igualdade de oportunidades. Os princípios desses acordos começam a ser incorporados à legislação brasileira, a partir da LDBEN nํ 9.394/96 e nas resoluções, pareceres e decretos que decorreram dessa lei. Assim, considera-se que 
a partir da década de 90 , inúmeras mudanças legais e conceituais, assentadas na defesa ao direito de todos à educação, começam a ser elaboradas pela via de programas e políticas educacionais.

Um dos marcos importantes na defesa ao direito de todos à educação, foi a PNEE (BRASIL, 2008), pois esta reflete as discussões realizadas sobre a inclusão de pessoas com deficiência no país. $O$ documento configura a educação inclusiva como uma ação política, cultural, social e pedagógica, em defesa ao direito à uma educação de qualidade e à organização de um sistema educacional inclusivo.

Tendo como referência a PNEE (BRASIL, 2008), em 2009, o estado de SC, atualizou a Política de Educação Especial/SC, instituindo serviços para o público da educação especial.

Mediante a atualização da Política, a educação especial no Estado, passa a ser concebida como "uma modalidade que perpassa todos os níveis, etapas e outras modalidades de ensino, sem substituí-los, ofertando os recursos e serviços de acessibilidade aos estudantes segundo o seu público." (SANTA CATARINA, 2015, p.71). Considerando o caráter transversal da educação especial em todos os níveis e modalidades de ensino, cabe destacar que a inclusão de pessoas com deficiência nas classes comuns e na modalidade EJA em SC, está ocorrendo de maneira mais acentuada nos últimos anos, como consequência da ampliação do acesso ao ensino regular. Os dados são apresentados na figura abaixo.

Figura 1- Matrículas Classes Comum e EJA- SC-2007/2013

\begin{tabular}{|c|c|c|c|c|c|c|c|c|c|c|}
\hline \multirow[t]{2}{*}{ Ano } & \multicolumn{5}{|c|}{$\begin{array}{c}\text { Classes Comuns do Ensino Regular e/ou da Educação de } \\
\text { Jovens e Adultos }\end{array}$} & \multicolumn{5}{|c|}{ Classes Especiais + Escolas Exclusivamente Especializadas } \\
\hline & Total SC & Municipal & Estadual & Federal & Privada & Total SC & Municipal & Estadual & Federal & Privada \\
\hline 2007 & 9.596 & 5.789 & 3.160 & 22 & 625 & 17.197 & 187 & 1.181 & 17 & 15.812 \\
\hline 2008 & 12.498 & 7.659 & 3.974 & 49 & 816 & 17.296 & 337 & 1.153 & & 15.806 \\
\hline 2009 & 12.432 & 7.508 & 4.202 & 74 & 648 & 1.263 & 51 & 414 & & 798 \\
\hline 2010 & 15.647 & 9.036 & 5.670 & 58 & 883 & 1.359 & 6 & 235 & 11 & 1.107 \\
\hline 2011 & 18.339 & 10.665 & 6.437 & 59 & 1.178 & 1.369 & 12 & 146 & & 1.211 \\
\hline 2012 & 20.001 & 11.837 & 7.196 & 73 & 895 & 1.295 & 32 & 75 & & 1.188 \\
\hline 2013 & 21.068 & 12.170 & 7.763 & 88 & 1.047 & 1.330 & 31 & 30 & & 1.269 \\
\hline
\end{tabular}

Fonte: Plano Estadual de SC/2015.

Segundo o Plano Estadual de SC (2015, p. 55), "nos dados pode-se constatar que o número de matrículas desses estudantes, nas classes comuns do ensino regular e/ou da educação de jovens e adultos, aumentou 119,55\%, no comparativo de 2013 com 2007." Diante dos dados compreende-se que os jovens e adultos com deficiência no estado de 
SC, estão buscando seu espaço nos CEJAs ${ }^{1}$. Nesse espaço buscam a escolarização e a certificação, que teoricamente o colocaria no mercado de trabalho, resgatando sua autoestima e o desenvolvimento humano e social. Mediante a inclusão no CEJA, entendese que esta instituição se tornou um novo território para jovens e adultos com deficiência. Neste contexto cabe questionar: Que processos são vivenciados pelos jovens com deficiência intelectual incluídos nos Centros de Educação de Jovens e Adultos?

Para responder ao questionamento, buscou-se, considerar o CEJA, como território. Ao considerar esta instituição como território, pensa-se que está se constitui na territorialidade de seus atores, entre os quais se destaca os jovens e adultos com deficiência intelectual.

Estudos sobre territórios abrangem um grupo heterogêneo de abordagens que questionam a concepção tradicional da geografia, colocando em pauta a constituição do território a partir de ações dos sujeitos no espaço. Haesbaert (2009) ao comentar sobre amplitude do conceito de território, que é central para a geografia, apresenta possibilidades de pensar este conceito com outras relações.

Território e territorialidade, por dizerem respeito à espacialidade humana, têm uma certa tradição também em outras áreas, cada uma com enfoque no território, em uma determinada perspectiva. Enquanto o geógrafo tende a enfatizar a materialidade, em suas múltiplas dimensões... a Ciência Política enfatiza sua construção a partir das relações de poder... a Economia, que prefere a noção de espaço à de território, percebe-o muitas vezes como um fator locacional ou como uma das bases da produção (enquanto força produtiva);a Antropologia destaca a sua dimensão simbólica... a Sociologia o enfoca a partir de sua intervenção nas relações sociais, em sentido amplo, e a Psicologia, finalmente, incorpora-o no debate sobre a construção da subjetividade ou identidade pessoal, ampliando-o até a escala do indivíduo. (HAESBAERT, 2009, p.37)

Ao remeter o conceito de território à educação, Franco (2003) ressalta que este abriga relações entre pares que se mostram opostos e complementares e que são convidados a coexistirem e influenciarem-se mutuamente na materialidade e imaterialidade; na complexidade e unicidade; na diversidade e identidade; na inclusão e exclusão; no espaço e tempo, global e local, urbano e rural, indivíduo e sociedade. A gama de relações que envolvem o conceito de território é confirmada por Saquet (2010), ao mencionar que,

Território é natureza e sociedade: não há separação: é economia, política e cultura; edificação e relações sociais; des-continuidades; conexão e redes; domínio e subordinação; degradação e proteção ambiental, etc. Em outras

\footnotetext{
${ }^{1}$ Em Santa Catarina, a modalidade da Educação de Jovens e Adultos, passou a denominar-se Centro de Educação de Jovens e Adultos (CEJA), adequando-se a LDBN/96, atendendo nos níveis de alfabetização, Nivelamento, Ensino Fundamental e Médio." (SANTA CATARINA, 2005, p.120).
} 
http://dx.doi.org/10.5902/1984686X24095

palavras, o território significa heterogeneidade e traços comuns, apropriação e dominação historicamente condicionadas; é produto e condição histórica e trans-escalar; com múltiplas variáveis, determinações, relações e unidade. É espaço de moradia, de produção de serviços, de mobilidade, de desorganização, de arte, de sonhos, enfim, de vida (objetiva e subjetivamente). O território é processual e relacional, (i) material, com diversidade e unidade, concomitantemente. (SAQUET, 2010, p.83)

$\mathrm{Na}$ definição que envolve o conceito de território, entende-se que esta, traz à tona a territorização. A territorização segundo Saque (2007) se expressa no movimento do sujeito na produção do território. O autor ainda destaca que, este processo é construído pelo movimento histórico, no qual o território é produzido socialmente. Nessa produção social, Saque (2007, p.58), destaca que "os processos sociais e naturais, e mesmo nosso pensamento, efetivam-se com a territorialidade cotidiana. É neste nível, que se dá o acontecer da nossa vida, e é nesta que se concretiza a territorialidade".

Na relação entre território e territorialidade, Haesbaert e Bruce (2009) mencionam que Deleuze e Guattari consideram esses conceitos importantes ferramentas para 0 entendimento não apenas de questões filosóficas, mas também das práticas sociais, da libertação dos desejos, dos corpos, da arte e da produção da subjetividade. O mencionado pelos autores é afirmado por Felix Guatarri no livro “Micropolítica: Cartografias do Desejo”, onde consta que território:

é entendido num sentido muito amplo, que ultrapassa o uso que fazem dele a etologia e a etnologia. Os seres existentes se organizam segundo territórios que se delimitam e os articulam aos outros existentes e aos fluxos cósmicos. O território pode ser relativo tanto a um espaço vivido, quanto a um sistema percebido no seio do qual um sujeito se sente "em casa". O território é sinônimo de apropriação, de subjetivação fechada sobre si mesma. Ele é o conjunto de projetos e representações nos quais vai desembocar, pragmaticamente, toda série de comportamentos, de investimentos, nos tempos e nos espaços sociais, culturais, estéticos, cognitivos. (GUATTARI; RONILK, 2010, p.388)

Os autores mencionam que o território ao ser considerado sinônimo de apropriação e subjetivação pode,

[...] se desterritorializar, isto é, abrir-se, engajar-se em linhas de fuga e até sair do seu curso e se destruir. A espécie humana está mergulhada num imenso movimento de desterritorialização, no sentido de que seus territórios "originais" se desfazem ininterruptamente com a divisão social do trabalho, com a ação dos deuses universais que ultrapassam os quadros da tribo e da etnia, com os sistemas maquínicos que a levam a atravessar cada vez mais rapidamente, as estratificações materiais e mentais. (GUATTARI; RONILK, 2010, p.388)

Sobre o movimento de desterritorização, em entrevista Deleuze afirma:

[...] precisamos, às vezes, inventar uma palavra bárbara para dar conta de uma noção com pretensão nova. A noção com pretensão nova é que não há 
http://dx.doi.org/10.5902/1984686X24095

território sem um vetor de saída do território e não há saída do território, ou seja, desterritorialização, sem, ao mesmo tempo, um esforço para se reterritorializar em outra parte. (DELEUZE apud HAESBAERT, 2009, p.1)

Os conceitos de Deleuze e Guattarri evidenciam o reconhecimento do movimento e da mudança, em que um território é abandonado e outro é construído. Nesse movimento "as territorialidades são, pois, atravessadas, de um lado a outro, por linhas de fuga que dão prova da presença, nelas, de movimentos de desterritorização e reterritorização." (DELEUZE; GUATTARI, 1997, p.71)

\section{Movimentos de desterritorização e reterritorização vivenciados por jovens com deficiência intelectual incluídos no ceja}

Criar um novo território é se aventurar, é trilhar caminhos diferentes, é sair do espaço sedentário, é encontrar através da expressividade novas possibilidades. Na busca de novas possibilidades, jovens com deficiência intelectual, estão aventurando-se, desterritorizandose e buscando novos territórios. A inclusão da maioria destes jovens, em novos territórios, tornou-se possível após a promulgação da PNEE (BRASIL, 2008). Política esta, que defende a organização de um sistema educacional inclusivo.

Mediante a organização do sistema educacional, os jovens com deficiência intelectual, estão frequentando a modalidade da EJA, na busca da escolarização, que teoricamente o colocariam no mercado de trabalho, resgatando sua autoestima e o desenvolvimento humano e social. Frente à um novo território, estes jovens, assim como qualquer jovem, apresentam anseios e desejos, como mencionaram ao remeterem-se ao CEJA:

\footnotetext{
Quero aprender a escrever aqui nessa escola. (jovem 1)

Quero terminar de estudar aqui no EJA. Aqui é legal. E depois fazer um curso de empacotador de mercado e vou trabalhar. [...](jovem 2)

Olha professora!! Vou terminar aqui, gosto daqui. E fazer uns cursos para trabalhar, quero ganhar dinheiro para comprar roupa..... (jovem 3)
}

Os jovens (1, 2 e 3), expressaram seus desejos. Desejos estes, que envolvem a escolarização e o término desta, a qualificação profissional, a inserção no mercado de trabalho e o consumismo. Entende-se na perspectiva deuleziana, que o desejo é algo construído. O desejo não é espontâneo, só há desejo anunciado e maquinado. Mas para que o desejo se transforme em uma máquina social, torna-se necessário que "as condições socioculturais engendrem modos de subjetivação, que favoreçam as condições para a produção do desejo." (DELEUZE; GUATTARI, 1997, p.86). 
http://dx.doi.org/10.5902/1984686X24095

Sobre os desejos, Haesbaert e Bruce (2009), destacam que são os desejos que criam os territórios. No que concerne a criação de territórios por meio dos desejos, o Jovem 3 menciona "Por isso eu to aqui eu quero ir trabalhar." O jovem ao expressar o desejo de trabalhar, evidencia a relação estabelecida entre os corpos, ou seja, o território CEJA, proporciona a realização de seus desejos. E é nessa relação entre corpos, que ocorre a construção do território.

Na construção do território, Haesbaert e Bruce (2009), destacam a importância dos agenciamentos. Agenciamentos de acordo com Deleuze e Guattari (1997, p.31) "se remetem a um estado preciso de mistura de corpos em uma sociedade, compreendendo todas as atrações e repulsões, as simpatias e as antipatias, as alterações e as expansões que afetam os corpos uns em relação aos outros". Os autores ainda destacam que os agenciamentos são formados por agenciamento coletivo de enunciação e agenciamento maquínico de corpos.

O agenciamento coletivo de enunciação se remete "à um regime de signos, à uma máquina de expressão cujas variáveis determinam o uso dos elementos da língua" (DELEUZE e GUATTARI, 1995, p.32). Os autores ao destacarem o conceito de agenciamento coletivo de enunciação, retomam a noção de discurso indireto de Bakhtin (2000) enfatizando que há muitas vozes em uma voz, pois todo discurso é indireto. Esse caráter coletivo da linguagem indica que mesmo em uma escrita individual há muitas vozes em diálogo. O agenciamento coletivo de enunciação é evidenciado nas falas dos jovens ao relatarem que,

A mãe falou que eu acabando aqui, eu vou trabalhar. Ainda não sei onde, mas eu vou trabalhar. (Jovem 1).

Minha mãe falou que quando eu sair daqui, eu vou trabalhar lá no mercado. Eu vou empacotar. E eu vou!!! Os lugares precisam de gente igual a eu para trabalhar.(Jovem 2).

Os jovens destacam as relações, que se efetivam no socius, os signos compartilhados e a linguagem. Essas relações estão presentes nas expressões de suas mães e familiares, nos anúncios de empregos, nos panfletos, jornais, TV, ou seja, na mídia. Esses elementos de agenciamento podem produzir fluxos dialógicos e fluxos afetivos. Fluxos estes que podem indicar processos de produção de subjetividade. Portanto, a subjetividade, pode ser produzida, também, pelos agenciamentos de enunciação, devido à multiplicidade de posições enunciativas, potencializando (pelos cruzamentos entre esses heterogêneos) os modos de enunciar. Os elementos de agenciamento coletivo, segundo Deleuze e Guattari 
http://dx.doi.org/10.5902/1984686X24095

(1997), constituem o pensamento, que se relaciona em uma constante com o agenciamento maquínico.

O agenciamento maquínico de corpos são as máquinas sociais, as relações entre corpos humanos, corpos animais e corpos cósmicos. Este agenciamento se constrói na relação entre os corpos, seja em "um regime alimentar, um regime sexual, regulam, antes de tudo, mistura de corpos obrigatórias, necessárias ou permitidas." (DELEUZE e GUATTARI, 1995, p.31). No que concerne este agenciamento, os jovens entrevistados expressam que:

Quero terminar de estudar aqui na EJA. [...]. E depois fazer um curso de empacotador de mercado e vou trabalhar. (jovem 2)

[..]Vou terminar aqui pegar o diploma, [...]. E fazer cursos para trabalhar, quero ganhar dinheiro para comprar roupa......... (jovem 3)

Os jovens anunciam o agenciamento maquínico, ou seja, seus desejos. Desejos relatados anteriormente, que focam na escolarização, na formação profissional, no mercado trabalho e no consumismo. Deleuze (1995) diz que o desejo não é uma determinação "natural", nem "espontânea". Assim entende-se que o desejo é agenciado e maquinado. 0 desejo nasce de um encontro, de um acontecimento e experimentação, expressão de composição maquínica, que envolve relação, afetos e devir.

Assim, entende-se o desejo como produção maquínica infinita, que se circunscreve como elemento de superação da fórmula psicanalítica do sonho e da fantasia, que domina o inconsciente. Relacionado aos desejos, o Jovem 2, afirma que "[...]quero ganhar dinheiro para comprar roupa igual meu irmão. Meu irmão compra roupa. Ele já tem até carro. Igual o carro que tem na televisão."

Mediante o exposto pelo jovem, cabe destacar verbos importantes ao se pensar na produção da subjetividade. Verbos, como agenciar, contagiar e imitar O imitar, o reproduzir, na concepção deleuziana, não significa fazer igual, pois

\begin{abstract}
A reprodução do mesmo não é um motor dos gestos. Sabe-se que até mesmo a mais simples imitação compreende a diferença entre o exterior e o interior. Mas ainda, a imitação tem apenas um papel regulador secundário na montagem de um comportamento permitindo não instaurar, mas corrigir movimentos que estão em vias de se realizar. A aprendizagem não se faz na relação da representação com a ação (com reprodução do mesmo), mas na relação do signo com a resposta (com o encontro com o outro). (DELEUZE, 1988, p. 54)
\end{abstract}

Compreende-se que a atitude do outro, os afetos alegres ou tristes produzidos nas relações podem provocar agenciamentos, aumentando ou diminuindo a potência de agir. Esses agenciamentos são entendidos por Deleuze e Guattari (1995), como uma força 
http://dx.doi.org/10.5902/1984686X24095

criadora e produtiva para formação do território, onde se articulam enquanto desejo e pensamento, assim como evidenciado pelos jovens.

Nesta perspectiva Deleuze e Guattari (1995), afirmam que os agenciamentos se relacionam reciprocamente, percorrendo um ao outro, sem hierarquia. Nesse movimento de reciprocidade entre os agenciamentos, um território se constitui.

$\mathrm{Na}$ constituição do território, Haesbaert e Bruce (2009) mencionam que os agenciamentos maquínicos e os agenciamentos coletivos de enunciação, são apenas dois dos quatro componentes na formação do território. A formação do território ainda se constitui pela desterrritorização e pela reterritorização.

A desterritorização, segundo Deleuze e Guattari (1997, p.224) é o "movimento pelo qual se abandona o território, é a operação da linha de fuga. A reterritorização é o movimento de construção do território." Os autores ainda destacam que, a desterritorialização constitui uma linha de fuga que não se aplica unicamente ao território, mas às forças e operações. Este movimento inclui também uma reterritorialização, como resultado de seu movimento e conexões.

Segundo os autores, na construção do território, os agenciamentos se desterritorizam, como o mencionado pelo Jovem 1 ao anunciar que não quer mais frequentar a instituição especializada. "eu não quero voltar para a APAE. Lá na APAE eu só rasgava papel, cortava, colava." emergindo "linhas de fuga"; linhas onde se encontram pensamentos e desejos.

Para Deleuze e Guattari (1997), o pensamento se faz no processo de desterritorização. Assim, entende-se que pensar é desterritorizar. "Pensar não é um fio estendido entre o sujeito e o objeto, nem uma revolução de um entorno ao outro. Pensar se faz antes da relação entre o território e a terra" (DELEUZE e GUATTARI, 1992, p.113). Neste sentido, compreende-se que a desterritorialização faz parte de um movimento infinito do pensamento, onde "jamais nos desterritorizamos sozinhos[...]" (DELEUZE e GUATTARI, 1996, p.41).

Os autores destacam a desterritorização em dois momentos: a desterritorização relativa e a desterritorização absoluta.

A desterritorialização relativa ocorre ao conectar a terra ao território mediante processos que se operam de forma física, psicológica ou social. Esse processo é o próprio socius. Isso significa dizer que a vida é um constante movimento de desterritorização, pois no cotidiano é comum passarmos de um território ao outro. Nessa constante, o que se modifica é a escala espacial e a temporalidade. Toma-se como exemplo para explicar a 
http://dx.doi.org/10.5902/1984686X24095

desterritorização relativa, os sujeitos desta pesquisa, os jovens com deficiência intelectual, que no decorrer de seu dia atravessam basicamente dois territórios: o território familiar e o território do CEJA. Territórios estes, onde os jovens vivenciam agenciamentos maquínicos de corpos e agenciamentos coletivos de enunciação distintos. Nesse processo, cabe destacar que os territórios não são destruídos pelos jovens, eles são abandonados temporariamente, se tornando lugares de passagem.

A desterritorização absoluta ocorre na composição imediata da terra às conexões e efetuações do pensamento. Para Deleuze e Guattari (1997, p. 225-226), o “absoluto nada exprime de transcedente ou indiferenciado, nem mesmo exprime uma quantidade que ultrapassaria qualquer quantidade (relativa). Exprime apenas um tipo de desterritorização que se distingue qualitativamente do movimento relativo."

$\mathrm{Na}$ relação entre o pensamento, desejo e a desterritorização absoluta, ocorre a ruptura com o território existente e a criação de um novo território, ou seja, a reterritorização. Nesse processo são necessários novos agenciamentos, novos encontros e novas funções, assim como anunciado pelo jovem, "Eu gosto de ficar aqui nessa escola, aqui eu escrevo, faço várias atividades. [...] A professora ainda falou que vou ainda trabalhar se eu quiser"(jovem 1). Ao se reterritorializar no CEJA, o jovem relata "Aqui todo mundo esta aprendendo igual eu." envolvendo-se com seus integrantes, assumindo os desafios e identificando-se com o grupo. Frente ao processo de desterritorização e reterritorização, entende-se estes, como processos indissociáveis e simultâneos, que não ocorrem de forma individual, sendo potencializado pelos agenciamentos e pelos encontros proporcionados pela inclusão.

\section{Considerações Finais}

O presente artigo emergiu a partir do seguinte questionamento: Que processos são vivenciados pelos jovens com deficiência intelectual no contexto da inclusão escolar?

Compreende-se que a partir da promulgação da PNEE (BRASIL, 2008), a inclusão de jovens com deficiência está ocorrendo de maneira mais acentuada na modalidade da Educação de Jovens e Adultos. Nesta perspectiva entende-se que a inclusão está possibilitando a descoberta de novos territórios. Na descoberta de um novo território, emergem expectativas, desejos e anseios, que foram evidenciados pelos jovens.

A criação deste novo território foi motivada por agenciamentos. Agenciamentos que se articulam enquanto desejo e pensamento percorrendo um ao outro, sem hierarquia. É 
nesse movimento que o jovem com deficiência intelectual constituiu o território, no CEJA, reterritorizando-se.

Mediante a reterritorização no CEJA, os jovens evidenciaram que a atitude do outro, os afetos alegres ou tristes produzidos nas relações podem provocar agenciamentos, aumentando ou diminuindo a potência de agir.

A inclusão no CEJA, possibilitou aos jovens com deficiência intelectual a descoberta de novos territórios. Nessa descoberta, os jovens vivenciam processos de desterritorização e reterritorização. Na desterrritorização, emergem as linhas de fuga, perfilhando uma relação entre o desejo e o pensamento, a terra e o território, onde as experiências vivenciadas na escola especial são acompanhadas pela reterritorização no CEJA. Por meio destes processos os jovens com deficiência intelectual, fazem parte do devir que a inclusão escolar possibilita.

\section{Referências}

BAKHTIN, M. Estética da Criação Verbal. 4. ed. São Paulo: Martins fontes, 2000.

BAUER, M. W.; GASKELL, G. Pesquisa qualitativa com texto, imagem e som. Rio de Janeiro: Vozes, 2002.

BRASIL. Constituição da República Federativa do Brasil. Brasília; Imprensa Oficial, 1988.

BRASIL. Declaração de Salamanca e linha de ação sobre necessidades educativas especiais. Brasília: UNESCO, 1994.

BRASIL. Lei de Diretrizes e Bases da Educação Nacional. Lei n. 9.394, de 20 de dezembro de 1996. D.O.U. de dezembro de 1996. Florianópolis: Sindicato das Escolas Particulares de

Santa Catarina, 1996.

BRASIL. Documento subsidiário à política de inclusão. Ministério da Educação. Secretaria de Educação Especial, Brasília - 2007, p. 47-48.

BRASIL. Política nacional de educação especial na perspectiva da educação inclusiva. Documento elaborado pelo Grupo de Trabalho nomeado pela Portaria Ministerial n. 555, de 5 de junho de 2007, prorrogada pela Portaria n. 948, de 09 de outubro de 2008. Brasília, 2008.

CARVALHO, R. E. Educação inclusiva com os pingos nos is. Porto Alegre: Mediação, 2004.

DELEUZE, G.; GUATTARI, F. O que é a filosofia? Lisboa: Presença, 1992. 
DELEUZE, G.; GUATTARI, F. Mil Platôs: capitalismo e esquizofrenia. Vol.1. Rio de Janeiro: Ed. 34, 1995.

DELEUZE, G.; GUATTARI, F. Mil Platôs: capitalismo e esquizofrenia. Vol. 3. Rio de Janeiro: Ed. 34, 1996.

DELEUZE, G.; GUATTARI, F. Mil Platôs. V 5. Rio de Janeiro. Ed. 34. 199

DELEUZE, G.; GUATTARI, F. O Inconsciente Maquínico: ensaios de esquizo-análise. Campinas: Papirus. 1988

DELEUZE, Giles; PARNET, Claire. Diálogos. São Paulo: Editora Escuta, 1998.

FRANCO, Maria Amélia Santoro. Pedagogia como ciência da educação. São Paulo: Papirus, 2003.

GUATTARI Félix; RONILK, Suely. Micropolítica: cartografias do desejo. 10.ed. Petrópolis, Rio de Janeiro: Vozes, 2010.

HAESBAERT, Rogério; BRUCE, Glauco. A desterritorialização na obra de Deleuze e Guattari. Revista GEOgraphia, Niterói, ano IV, n.7, p.7-31, 2009.

HAESBAERT, Rogério O mito da desterritorialização: do "fim dos territórios" à multiterritorialidade. 4.ed. Rio de Janeiro: Bertrand Brasil, 2009.

INSTITUTO NACIONAL DE ESTUDOS E PESQUISAS EDUCACIONAIS ANÍSIO TEIXIERA. Resumo do Censo Escolar. 2013. Disponível em: http//portal.inep.gov.br/básica-levantamentos-microdados. Acesso em 23 de maio de 2015.

SANTA CATARINA, Secretaria de Estado da Educação, Ciência e Tecnologia. Proposta Curricular de Santa Catarina: Estudos Temáticos. Florianópolis: IOESC, 2005.

SANTA CATARINA, Secretaria de Estado da Educação, Ciência e Tecnologia. Plano Estadual de Santa Catarina. Elaboração: Secretaria de Estado da Educação: IOESC, 2015.

SAQUET, M. A. As diferentes abordagens do território e apreensão do movimento e da

(i)materialidade. Geosul, Florianópolis, v.22, n.43, p.55-76, jan./jun. 2007.

SAQUET, M. A. Abordagens e concepções de território. 2.ed. São Paulo: Expressão Popular, 2010.

UNESCO. Declaração de Salamanca sobre princípios, políticas e prática em educação especial. Espanha, 1994. 
UNESCO. Declaração Mundial sobre educação para todos: plano de ação para satisfazer as necessidades básicas de aprendizagem. Jomtien, 1990.

\section{Correspondência}

Valéria Becher Trentin - Rua: Bernardino João Victorino, № 27. Apartamento 1003. Bairro: Centro. CEP: 88303-090. Itajaí, Santa Catarina, Brasil.

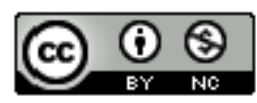

This work is licensed under a Creative Commons Attribution-NonCommercial 4.0 International (CC BY-NC 4.0) 